\title{
Research and Design of Fault Indicator Using Comprehensive Detection and Identification Method
}

\author{
Ning Xia ${ }^{1}$ a , Lei Zhang ${ }^{1}$, Chen Chen ${ }^{1}$, He Zhang ${ }^{1}$, Changsong $\mathrm{Ni}^{1}$, Liangxu $\mathrm{He}^{1}$ \\ ${ }^{1}$ State Grid Dalian Power Supply Company, Power Supply Service Command Center,116000 Dalian, China
}

\begin{abstract}
With the progress and development of society, the power supply quality of power system is required to be higher and higher. It is necessary to locate the fault and remove it quickly. Therefore, it is necessary to install fault indicator on distribution line to improve the efficiency of finding fault location. As an important part of distribution network, the $10 \mathrm{kV}$ overhead line has the characteristics of many branches, wide coverage area, time-consuming and labor-consuming in line inspection and maintenance. The fault indicators currently used have problems such as complex structure, high cost of installation and deployment, and inaccurate fault detection. In this paper, a new type of fault indicator is proposed, which uses the comprehensive fault detection method. DSP processor is used to collect, calculate and process the voltage and current information of power grid. Through the embedded programming language, the comprehensive fault detection and identification is realized. Finally, the acquisition accuracy and fault judgment accuracy of the fault indicator are tested by simulating the fault signal in the laboratory. The experimental results show that the proposed fault indicator has high accuracy and can meet the requirements of fault indication, location and alarm.
\end{abstract}

\section{Introduction}

Automation construction can comprehensively improve the management level of the distribution network, and can combine the operation state of the distribution network, especially the fault state, with the actual line to ensure the rapid and accurate fault repair, so as to ensure the stable operation of the distribution network ${ }^{[1-2]}$.

In this context, power supply enterprises have increasingly higher requirements for the ability to locate faults in the distribution network, and one of the key issues affecting the reliability of the distribution network is how to locate faulty lines ${ }^{[3-6]}$. The traditional fault location can only rely on manual line patrol to find the fault point. This way causes many problems such as the distribution operation and maintenance personnel participating in the fault finding, long processing time and so on. It causes a great waste of human, material and financial resources, and there are some technical defects in the detection methods ${ }^{[7-9]}$. Fault indicator is one of the common devices in the working process of distribution network. Its main working principle is to judge and identify the specific location of line fault through accurate detection of fault current characteristics. When singlephase grounding short circuit fault occurs in a line, the distribution operation and maintenance personnel can operate with the help of the specific location of the fault indicator, determine the fault section and the fault location quickly and accurately, which greatly speeds up the efficiency and accuracy of fault finding ${ }^{[10-12]}$.
Compared with developed countries such as Europe and America, the research on fault indication in China started late. At present, there are still few studies in this field in our country, and there are still many problems in the use of fault indicators. Some installed fault indicators occasionally malfunction and refuse to operate. There is still much room for the development of domestic equipment in terms of positioning accuracy, detection sensitivity and working reliability. The traditional fault indicators usually adopt analog circuit mode, using 8051 series single chip microcomputer as controller, so there are some limitations in the technology itself. The processing power of the device is weak, which leads to its simple function.

This paper first introduces four kinds of typical short circuit faults in distribution network, and briefly describes their fault characteristics. At the same time, several typical fault indicator detection methods of distribution network are introduced. By comparing and analyzing the characteristics of different detection methods, this paper proposes a fault indicator based on various fault detection methods, which can collect and analyze the fault current characteristics and judge the fault type through DSP. The fault signal is simulated in the laboratory, and the current acquisition accuracy and fault type judgment accuracy of the fault indicator are tested. The experimental results show that the proposed fault indicator has high accuracy and can meet the requirements of fault indication and alarm.

a Ning Xia: laojin2193@163.com 


\section{Detection and identification method}

This section introduces the typical short circuit faults in the distribution network, and explains their fault characteristics. A variety of fault detection methods for distribution network are introduced, and a comprehensive fault detection method based on fifth harmonic method, first half wave method and over-current principle is proposed.

\subsection{Fault characteristics of distribution network}

As shown in Table 1, The faults of $10 \mathrm{kV}$ overhead lines are mainly divided into three-phase short circuit fault, two-phase grounding short circuit fault, two-phase to phase short circuit fault and single-phase grounding short circuit fault. The analysis of the fault characteristics can help to locate the fault quickly.

Table1. Typical fault types

\begin{tabular}{|c|c|c|}
\hline Fault types & $\begin{array}{c}\text { Probability } \\
\text { of occurrence }\end{array}$ & $\begin{array}{c}\text { Symmetry } \\
\text { type }\end{array}$ \\
\hline $\begin{array}{c}\text { Three-phase short } \\
\text { circuit fault }\end{array}$ & Very few & $\begin{array}{c}\text { Symmetrical } \\
\text { short circuit }\end{array}$ \\
\hline $\begin{array}{c}\text { Two-phase } \\
\text { grounding short } \\
\text { circuit fault }\end{array}$ & less & $\begin{array}{c}\text { Asymmetric } \\
\text { short circuit }\end{array}$ \\
\hline $\begin{array}{c}\text { Two-phase short } \\
\text { circuit fault }\end{array}$ & less & $\begin{array}{c}\text { Asymmetric } \\
\text { short circuit }\end{array}$ \\
\hline $\begin{array}{c}\text { Single-phase } \\
\text { grounding short } \\
\text { circuit fault }\end{array}$ & more & $\begin{array}{c}\text { Asymmetric } \\
\text { short circuit }\end{array}$ \\
\hline
\end{tabular}

The common phase-to-phase short circuit faults are two-phase short circuit fault and two-phase grounding short circuit fault. When two-phase short circuit fault occurs, the current of the fault phase increases to $\sqrt{3}$ times of the normal value, while the voltage of the fault phase is half of the normal value. The current of non-fault phase is 0 , and the voltage of non-fault phase remains unchanged. When two-phase grounding short circuit fault occurs, the current of the fault phase increases sharply and is larger than that of two-phase short circuit fault, while the voltage and current values of non-fault phase are 0 . we can judge whether it is two-phase grounding short circuit fault by analyzing the characteristics of voltage and current.

When single-phase grounding short circuit fault occurs, the current of fault phase and the voltage of nonfault phase increase. The single-phase grounding short circuit fault can be judged according to the variation characteristics of current and voltage.

The typical short circuit current is simulated by Matlab/Simulink. The current waveforms are shown in Figure 1 and the simulation model is shown in Figure 2.

The characteristics of fault current obtained by simulation can help to guide the design of fault indicator identification algorithm. Most of the faults in distribution network are single-phase grounding short circuit fault. The fault indicator of this paper is designed by analyzing single-phase grounding short circuit fault.

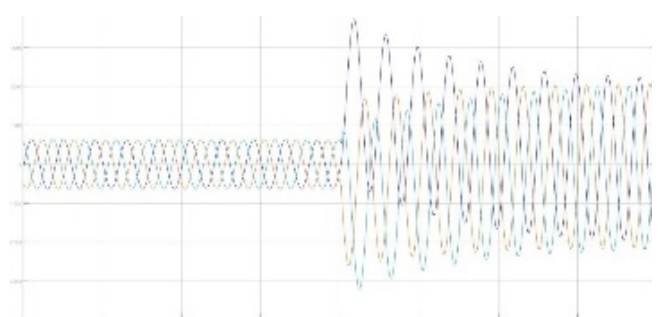

(a)

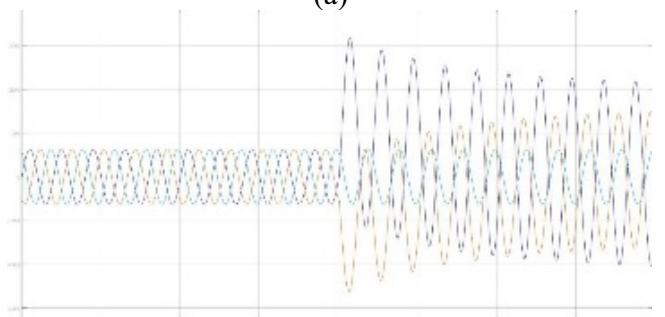

(b)

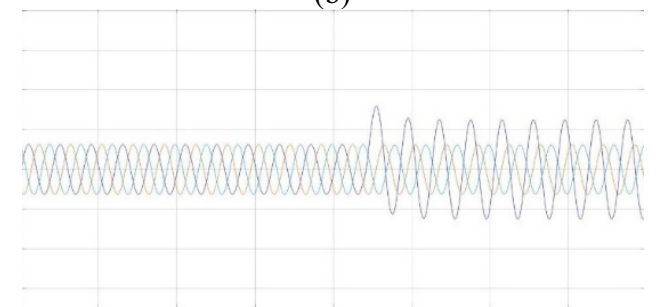

(c)

(a) Three-phase Short Circuit Fault

(b) Two-phase Short Circuit Fault

(c) Single-phase Grounding Short Circuit Fault

Fig 1. The Waveforms of Typical Short Circuit Current

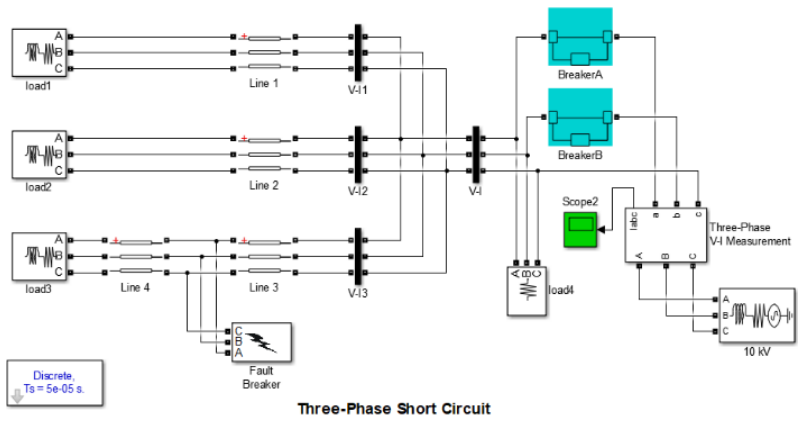

Fig 2. The Simulation Model by Matlab/Simulink

\subsection{Comprehensive detection and identification method}

Typical fault detection and identification methods mainly include first half wave detection method, 5th harmonic detection method, over-current detection method, variable load detection method and zero sequence current detection method. - The text should be set to single line spacing.

Most of the fault indicators are generally based on a single detection method for data analysis, which has certain limitations in practical application, resulting in inaccurate processing results and misjudgments. Therefore, the comprehensive detection and identification method is used to analyze the fault current, in order to improve the accuracy and stability of fault identification, considering the first half wave method, the fifth harmonic method and the over-current principle. 


\subsubsection{First half wave detection method}

The capacitive current at the grounding point flows from the fault point to the bus and then flows to each branch line through the bus in the initial half cycle of zero sequence current after the fault occurs. Therefore, the polarity of the first half wave peak value of the zero sequence current of the fault line is opposite to that of the non-fault line in the initial half cycle after the fault occurs. And the peak value of fault line is the sum of all non-fault lines. The fault line can be detected accurately by judging the polarity and amplitude of the first half wave of each line.

\subsubsection{Fifth harmonic detection method}

The fifth harmonic method is often used in the system grounded by arc suppression coil. The 5th harmonic current component will not be compensated by the arc suppression coil and the voltage of the fault phase will decrease when the line is grounded. The short circuit current will break down the virtual capacitance between the overhead line and the ground, resulting in the change of the 5th harmonic current component in the system. The 5th harmonic current of fault phase is the sum of that of all non-fault phases. The direction of fault phase current is opposite to that of non-fault line current. Therefore, the fault can be determined by comparing the magnitude and polarity of the fifth harmonic current.

\subsubsection{Over-current detection method}

The working principle of over-current principle is shown in Figure 3. The fault indicator will judge the fault of the line when the current of the line is greater than the preset current threshold.

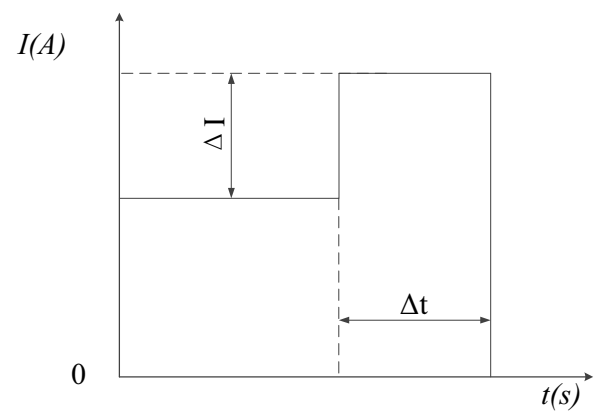

Fig 3. Over-current Detection Method

The fault detection process is as follows: When the ground fault occurs, the current of the fault phase is determined by the fifth harmonic method, the first half wave method and the over-current principle. If the judgment results of the three methods are consistent, the output results will be determined according to them; If not, output the result according to the principle that the minority is subordinate to the majority.

\section{Design and test of fault indicator}

The overall design of the system is proposed based on the above analysis in this section. The hardware platform is built and the identification function is completed by embedded system.

\subsection{Design and construction of experimental platform}

The structure of the new fault indicator is shown in the Figure 4.

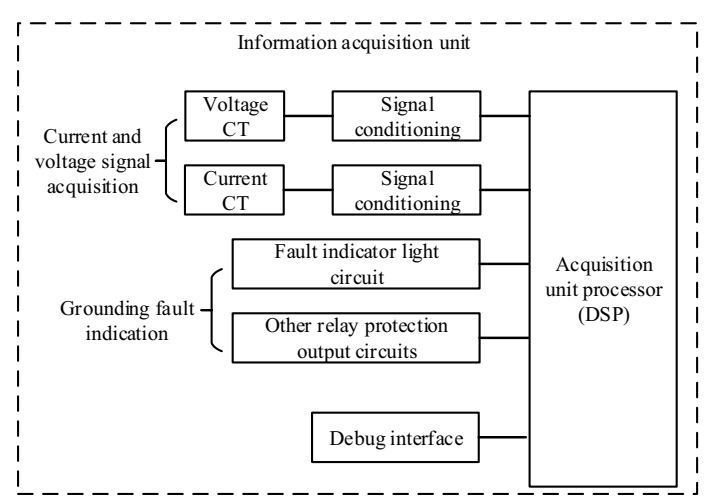

Fig 4. Structure Diagram of Controller

The grounding fault is simulated by transformer and resistance grounding in laboratory. The voltage transformer and current transformer collect the voltage and current, which are input to the DSP processor through the signal conditioning circuit. The fault is identified by the comprehensive detection principle, and the fault indicator judges the short circuit fault and outputs the judgment result.

The design of fault indicator motherboard based on DSP processor is shown in Figure 5. The circuit board introduces the transformer signal through the terminal, and indicates the fault information through the indicator light.

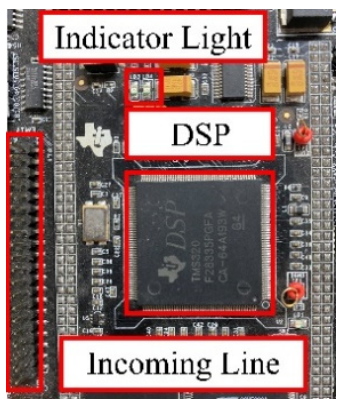

Fig 5. The motherboard of fault indicator

\subsection{Fault indication identification experiment}

The short circuit fault current waveform of distribution network is shown in Figure 6. The short circuit current simulated by transformer is the same as this waveform.

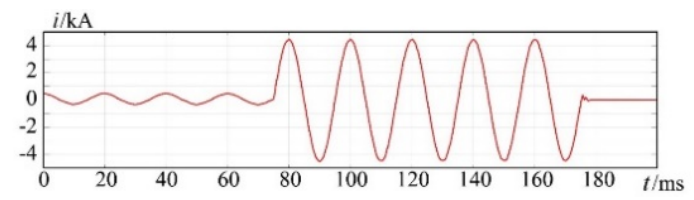

Fig 6. Typical short circuit fault current waveform 
In order to ensure the accuracy of the input signal, the output of the indicator is corrected by comparing the error between the measured value of the current clamp and the measured value of the indicator.

The experimental results are shown in Table 2. The experimental results show that the error between the measured value of the current clamp and the measured value of the indicator is less than $2 \%$, which will not affect the fault identification process.

Table2. Current measurement

\begin{tabular}{|c|c|c|}
\hline $\begin{array}{c}\text { Current clamp } \\
\text { measurement (A) }\end{array}$ & $\begin{array}{c}\text { Indicator } \\
\text { measurement } \\
(\mathrm{A})\end{array}$ & error \\
\hline 0 & 0 & 0 \\
\hline 2 & 2.004 & $+0.20 \%$ \\
\hline 4 & 3.991 & $-0.22 \%$ \\
\hline 6 & 5.924 & $-1.27 \%$ \\
\hline 8 & 8.025 & $+0.31 \%$ \\
\hline 10 & 9.909 & $-0.91 \%$ \\
\hline 12 & 12.134 & $+1.03 \%$ \\
\hline 14 & 13.833 & $-1.19 \%$ \\
\hline 16 & 15.850 & $-0.94 \%$ \\
\hline
\end{tabular}

Test the minimum identifiable short circuit fault current as shown in Table 3 .

Table3. The minimum identifiable short circuit fault current

\begin{tabular}{|c|c|c|}
\hline Phase & Load current (A) & $\begin{array}{c}\text { Measurement } \\
\text { result (A) }\end{array}$ \\
\hline A & 2.05 & 15.08 \\
\hline B & 1.99 & 14.98 \\
\hline C & 2.11 & 15.53 \\
\hline
\end{tabular}

Different types of grounding fault are tested to determine whether they can be correctly identified and whether they meet the requirements of measured values.

Table4. Grounding fault identification accuracy

\begin{tabular}{|c|c|c|}
\hline $\begin{array}{c}\text { Type of grounding } \\
\text { fault }\end{array}$ & $\begin{array}{c}\text { Number of } \\
\text { experiments }\end{array}$ & $\begin{array}{c}\text { Correct } \\
\text { identification } \\
\text { times }\end{array}$ \\
\hline $\begin{array}{c}\text { Metallic grounding } \\
\text { fault }\end{array}$ & 10 & 10 \\
\hline $\begin{array}{c}\text { Small resistance } \\
\text { grounding fault }\end{array}$ & 10 & 10 \\
\hline $\begin{array}{c}\text { High resistance } \\
\text { grounding fault } \\
\text { (less than } 1 \mathrm{k} \Omega \text { ) }\end{array}$ & 20 & 19 \\
\hline
\end{tabular}

\section{Conclusion}

This paper summarizes the research status of fault indicator at home and abroad, as well as the problems of fault indicator in practical work. Based on the analysis of various fault types, a new type of transient wave recording remote fault indicator is proposed. Aiming at the singlephase ground fault, a comprehensive fault detection method based on the fifth harmonic method, first half wave method and over-current principle is proposed. The function of fault indicator detection and recognition is realized by using embedded system. By simulating the fault signal in laboratory, the acquisition accuracy and fault judgment accuracy of fault indicator are tested. The experimental results show that the proposed fault indicator has high accuracy and can meet the requirements of fault indication and alarm.

\section{References}

1. W. Usida, D. Coury, R. Flauzino, Efficient Placement of Fault Indicators in an Actual Distribution System Using Evolutionary Computing, IEEE Transactions on Power Systems, 3(1), 621-622(2018).

2. L. Zhang, Y. Liang, Y. Sun, Y. Xue, L. Li, X. Jin, Fault Type Recognition of Over-head Lines of Distribution Networks Based on Fault Indicator Waveform Data, 2018 China International Conference on Electricity Distribution, 1444-1448(2018).

3. J. Gong. Analysis of the Design and Performance of Microcomputer Fault Alarm System, Journal of Physics, 1852(2)(2021).

4. F. M. Angerer, New developments in Faulted Circuit Indicators help utilities reduce cost and improve service, 2008 IEEE Rural Electric Power Conference, B4-B4-3(2008).

5. H. David. Theories for design and analysis of robust [formula omitted] fault detectors, Journal of the Franklin Institute, 358(1)(2021).

6. Y. Lin et al., A fault location method for feeder automation based on fault probability, 2017 4th International Conference on Electrical and Electronic Engineering, 120-123(2017).

7. R. Dashti, J. Sadeh, Fault indicator allocation in power distribution network for improving reliability and fault section estimation, 2011 International Conference on Advanced Power System Automation and Protection, 1406-1411(2011).

8. X. Zeng, X. Yin, New Principle for Grounding Fault Feeder Detection in MV Distributions with Neutral Ineffectively Earthed, Journal of southeast University (English Edition), June, 64 69(2000).

9. Z. Xu, J. Xin, J. Pan, et al, Research and application of new fault indicator test platform, Electrical Measurement \& Instrumentation, 56 (5): 124129(2019).

10. E. Pawel, O. Teresa, J. Kamila, Effectiveness Analysis of PMSM Motor Rolling Bearing Fault Detectors Based on Vibration Analysis and Shallow Neural Networks, Energies, 14(3)(2021).

11. A. Mani, K. Reihaneh, R. Mohammadreza, An adaptive fault detector strategy for scientific workflow scheduling based on improved differential evolution algorithm in cloud, Applied Soft Computing Journal, 99(2021).

12. F. Peng, Q. Yuan, Y. Liu, Research and application of new type fault indicator in smart distribution grid, 2014 China International Conference on Electricity Distribution, 67-69(2014). 